\title{
LACK OF POPULARITY IN AUGMENTED AND VIRTUAL REALITY APPLICATIONS FROM THE PERSPECTIVE OF USERS, POTENTIAL USERS AND NON-USERS
}

\author{
Guilherme Daguir ${ }^{1}$ and Fábio Campos ${ }^{2}$ \\ Federal University of Pernambuco, Recife, Brazil
}

\begin{abstract}
This study provides evidence on the possible barriers that affect the massification of solutions based on virtual reality (VR) and augmented (AR). To gather this evidence, nine sessions of Focus Groups were held with 43 people in total. Users of VR or AR applications, potential users and non-users were involved. The evidence obtained shows a plurality of entry barriers to decrease the lack of value perception related to applications using VR and AR. The majority of the sample shows a strong relation with theses technologies only with leisure and entertainment. Also some biases and less value of an immersive virtual reality for daily experiences or activities. However, AR was received better to daily purposes it was also not well connected with urban people routine in their perspective.
\end{abstract}

\section{KEYWORDS}

Perception, Feeling, Virtual Reality, Augmented Reality, Users

\section{INTRODUCTION}

With the popularization of the internet and increased processing power of desktops and laptops (desktops, notebooks and smartphones), easy access to a form of virtuality was achieved. However, familiarity with completely virtual worlds, through equipment with greater immersion potential (such as VR goggles), did not have the same popularity.

The virtuality has been studied and implemented for several decades. It is a matter of understanding reality with several steps up to a totally virtual world (VR). It is like a continuous line, where one end is however the real and physical world as it is now known, and along it points of interference of virtual elements, moving to the other end containing an artificially created reality by computer (Jason, 2016).

Virtual reality is defined to be a computer-generated digital environment that can be experienced and interacted through any sensory stimuli as if that environment were real (Jason, 2016). Augmented Reality (AR) is the mixing of virtual reality elements upon our everyday reality, usually done through a display, like a smartphone display.

Since 2008 augmented reality has been listed as one of ten technology that would change the way humans relate to computers (Trends, 2008). And the diminishing strangeness of systems that support these interactive formats in urban societies around the world is noticeable. However, augmented reality (AR) can be perceived in synchrony with virtual reality (VR) at this point of lack absorption by society (Erra, Malandrino, Pepe 2018). Both are not popular, routine and common in applications beyond casual entertainment.

Participatory design (or co-design), which involves the relationship with the user (Canina, 2011), it is also expressed here by the technique used (the Focus group) to get knowledge from the users perspective. The results from these experiments should help to power this way of problem exploration in the design process. It means to relate this phase of designing as a relationship with users in order to know about their perspective before constructing any project to them.

\footnotetext{
${ }^{1}$ gui.daguir@gmail.com

2 fc2005@gmail.com
} 
This document proposes to investigate this lack of familiarity of people with these technologies. The research carried out offers points of discussion that can lead some evidence on how to improve the interaction within this area, beyond the former goal of understanding what causes non-use of AR eVR in different groups.

\section{INSIGHTS AND PERCEPTION}

The applied research strategy was the use of the Focus Group qualitative technique. The Focus Group was chosen because of its flexibility of application and the ability to generate insights about the subject.

Focus group is a qualitative method often used in the design process in the phase of exploration of the problem or in analysis of solutions and prototypes. It is a dynamic created by a small group of well-chosen people, when guided by a skilled moderator, can provide deep insight into themes, patterns, and trends. This moderator guides the dialogue between the participants in order to maintain the discussion and achieve the objectives of that meeting. Participants in turn are free to discuss the proposed topics without fear of being judged is diminished. Participants are more likely to share experiences, stories, memories, perceptions, wants/needs, and fantasies, expectations, opinions, feelings (Martin, Hannington, 2012).

When analyzing focus group data, is recommended to pay particular attention to stories people tell, the metaphors and analogies they use, and how they describe their experiences, preferences, and memories. By looking for recurring topics and themes that produces strong responses, that can be analyze for trends and patterns (Martin, Hannington, 2012). This responses can be called insight, a popular word in design area related to some accurate or deep intuitive understanding of a target. Results from focus groups should never be extrapolated for how a whole population is or feels. It should be integrated with other qualitative or quantitative methods that can be realized in further experiments.

The study performed here, used the application of this technique to seek to understand the perspective of people divided in three groups. First group is the ones who often have contact and use of VR or AR applications (which we consider "users"). The second group are the ones who had some episodic contact with the technology and consider accessing it in the future (those we consider "potential users"). The third group have never experienced VR or AR (consider as "non-users").

The "user" group was composed of developers or early adopters of VR and AR applications (gamers, IT and design staff involved in the development of VR and AR solutions, content producers for VR and AR, etc).

The "potential users" group was composed of people who have already had the opportunity to use a VR or AR application in some situation and who are open to eventually reusing those technologies (several users who have experienced VR or AR at a trade show, for example, or in a game console of some known).

The "non-users" group was composed of people who had never experienced the use of VR or AR solutions. Some of them were not interested and other were open to experiencing the use of such solutions some day.

The following sections describes the experiment performed, detailing each session of Focus Groups.

\section{HOW THE FOCUS GROUP WERE PERFORMED}

The experiment was conducted this way, a group of volunteers undergraduate student designers that applied the focus group technique in a volunteer groups of participants invited by the designers. The total number of groups and focus group sessions were 9. The designers were organized in a way they could engage in the experiment, and were disposal for one week to deal it. Could be happened more sessions in this time but no more participants appeared or setted an appointment .

Characterizing the groups, the designers were about 20, between 1 and 4 years of experience in the area, were undergoing training. All of them received that month previous explanatory and practical training in relation to technique. Each team counted with at least 1 moderator, and the data were recorded through audio and video for further analysis. When the group had more than a person, the rest of the designers helped in the recording activity, prepare the room and write down the saved content, being helpful to quickly delivery of the data. As fewer the group fewer the speed.

The participant group were gather by the designers, they announcing the event to relatives, colleagues, in tourism spots and in front of university departments linked to the area of technology (computer science, engineering and design). The participating professions were in the areas of: Computer science, biology, 
architecture, physical education, dancers, physicians, teachers, self-employed professionals, students of computer science and design, electronics and computer technicians.

No gender or age specification was required for this activity. The designers asked the invited people about their relationship with VR and AR, and only if there were one of each group (users, potential users and non-users) this could be considered a session for the experiment. The concept of virtual reality and augmented reality considered for this article, holded by the designers and participantes, are explained in the introduction chapter one of this paper.

The total sample were 43 participants ranging from 8 to 65 years. One child, one 16-year-old adolescent, three elderly aged 60-65 years old, two middle-aged participants, one in 46 other in 55 years old, and 36 participants aged 18-30 years. A brief of all the evolved in the experiment can be readed in Table 1.

The focus groups occurred in 2018, in the city of Recife, Pernambuco, without the need for participants to be born in that city, but only native showed. A confidence interval and level were calculated by the Research System (Creative Research System, 2018), in order to compare how the discussion provided through this activity is reflected in level of fidelity in the Brazilian population. On this experiment we have a confidence interval of 15 and $95 \%$ confidence level reached.

The confidence interval is also called margin of error. The confidence level tells you how sure you can be. It is expressed as a percentage and represents how often the true percentage of the population who would pick an answer lies within the confidence interval. The $99 \%$ confidence level means you can be $99 \%$ certain. Most researchers use the 95\% confidence level (Creative Research System, 2018).

Who was available at the time and date marked were gone to the focus group events were available in the three shifts of the day, for a period of 7 days, these sessions not happened sequentially, each group has a particular hour to begin.

The experiment purposed was carried out in person. Exception for one group that applied it remotely due to request of all participants involved in that specific session. The procedure was conducted in the same way for all groups, so even the one which occured in online video chat had the same steps. All the session were analyzed in the same way here. Maybe further experiments could be realized in order to map variables and compare if answers provided from online way have different results.

In the first moment of the focus group the participants were advised about the recorder, and informed that activity will occur as a simple conversation and the review of the meaning of VR and AR has been said. The moderator started a conversation with the participants about VR and AR, and conduct them to talk about these topics below in the following order. If the groups starts to diverge, the moderator should bring them back naturally without instruct it. The reason for it is making all participants feel in a free environment to express their thoughts, as a casual chat. The guiding topics were:

1. Knowledge and general use of VR and AR;

2. Problems in the use of these technologies, and general technologies;

3. Applications and services that use VR and AR.

Table 1. Distribution of participants in the focus group experiment

\begin{tabular}{|l|c|c|c|c|c|c|c|c|c|}
\hline ID Group & A & B & C & D & E & F & G & H & I \\
\hline Designers evolved & 6 & 3 & 2 & 1 & 2 & 1 & 1 & 2 & 2 \\
\hline $\begin{array}{l}\text { Total number of } \\
\text { subjects in the sample } \\
\text { group }\end{array}$ & 7 & 4 & 4 & 4 & 5 & 3 & 6 & 5 & 5 \\
\hline $\begin{array}{l}\text { Range age of subjects } \\
\text { per group }\end{array}$ & $15-21$ & $18-65$ & $8-49$ & $21-26$ & $21-40$ & $28-46$ & $21-29$ & $18-65$ & $19-28$ \\
\hline
\end{tabular}

This study relied on data collection by undergraduate design students. The acquired data were punctuated in commented topics, that occurred with the proposed dialogue with the focus group participants, it can be seen in the next chapter (table 2). These topics were extensively described at the outset. And they were later reorganized into larger categories called here as "clustering topics". 
These clustering topics received scores equivalent to length of groups that raised those point of argument in the focus group session. That is, many questions emerged and each one counted as one, even when discussed twice or more within a single group.

A parallel between the clustering topics and theirs score, were made based on likert scale scores of importance (Vieira, Dalmoro, 2008).

Therefore,

$0 \%$ - 20\% Unimportant

$21 \%-40 \%$ Little important

$41 \%-60 \%$ Reasonably important

$61 \%-80 \%$ Important

$81 \%-100 \%$ Very important

Through this, none of the categories fitted as "unimportant" nor as "very important."

\section{RESULTS}

As explicated in the last chapter the talk between the participants in the focus group was conduct in the three major questions. These questions resulted in insights called here as "commented topics", each one have been ascertained by the designers team and these were organized in relation to group that they come from, and are reported in Table 2.

Table 2. Topics resultant from application of focus group

\begin{tabular}{|c|c|}
\hline ID Group & Commented Topics \\
\hline A & $\begin{array}{l}\text { Addiction in virtual reality. } \\
\text { Not practical. } \\
\text { Aversion to technologies. } \\
\text { Fears of misuse of people with the unfolding of technology. }\end{array}$ \\
\hline B & $\begin{array}{l}\text { Aversion to immersive virtual reality } \\
\text { Belief that technological evolution is always associated with future dystopic. } \\
\text { Utility for entertainment only. } \\
\text { Virtual reality would deepen social divisions. }\end{array}$ \\
\hline $\mathrm{C}$ & $\begin{array}{l}-\quad \text { Rejection of this type of technology for daily use. } \\
\text { Low usability of VR devices (headsets) for everyday use. } \\
\text { Consider immersive only applications that require a headset, disregarding AR. } \\
\text { - } \\
\text { headsets. }\end{array}$ \\
\hline $\mathrm{D}$ & $\begin{array}{l}\text { Excitement for using VR and AR daily with banal activities (eg snacking). } \\
\text { Ease of adaptation to AR because it is less immersive, and more useful for routine activities. }\end{array}$ \\
\hline $\mathrm{E}$ & $\begin{array}{l}\text { Perceive AR and VR just as entertainment. } \\
\text { Realize the negative points of the headsets as weight, and possibility of headache } \\
\text { Identify AR as easier for adaptation and day-to-day situations. } \\
\text { VR would be useful only for long-term experiences. }\end{array}$ \\
\hline $\mathrm{F}$ & $\begin{array}{l}\text { See in the AR and VR the future of technology. } \\
\text { Never used VR arguing, relating this to the need for a specific device. } \\
\text { Rejection to these technologies for fear of damage to health. } \\
\text { Understand that VR does not apply to routine activities, only at very specific moments in life. }\end{array}$ \\
\hline
\end{tabular}




\begin{tabular}{|c|c|}
\hline $\mathrm{G}$ & $\begin{array}{l}\text { Participants commented on the use of these technologies for serious purposes (education, training } \\
\text { etc) but in their daily lives perceived AR and VR only as entertainment possibilities. } \\
\text { AR and VR should be encouraged for training more often. } \\
\text { VR without utility for daily use. } \\
\text { Understand the peripherals (controls and headsets) as a fact of breaking in the immersion } \\
\text { experience. } \\
\text { argued that their high cost was a deterrent. } \\
\text { Fear of health damage caused by VR immersion with headset. }\end{array}$ \\
\hline $\mathrm{H}$ & $\begin{array}{l}\text { Little interactivity in AR applications on screens. } \\
\text { High cost of VR devices and no daily applicability. } \\
\text { - } \quad \text { AR and VR are only consistent for entertainment purposes. }\end{array}$ \\
\hline I & $\begin{array}{l}\text { Understand in AR and VR the future of technology, but not financially accessible at all. } \\
\text { Realize advantages in VR and AR applications for serious purposes. } \\
\text { Relate VR to teleportation and holograms. } \\
\text { Punctuate the evolution of AR and VR only in the universe of games. }\end{array}$ \\
\hline
\end{tabular}

\section{DISCUSSION}

The themes discussed were grouped into general categories in an attempt to understand the data in a quantitative perspective. These categories involving the topics discussed are detailed in Table 2, also in this tabulation is the relation of the quantity of groups of the experiment that approach this topic.

Using a Likert scale application (Vieira, Dalmoro, 2008) the categories were distributed according to the length of times that they were discussed. A category with more discussions per group was considered more important than another with less groups talked about it.

It is worth remembering that these categories and scores may prove different in new samplings. Further studies are encouraged with different subjects.

Table 3. List of emerging focus group topics

\begin{tabular}{|l|c|c|l|}
\hline Clustering topics & $\begin{array}{l}\text { Length of } \\
\text { groups that } \\
\text { addressed }\end{array}$ & $\begin{array}{l}\text { Percentage in total } \\
\text { number of } \\
\text { sampling groups }\end{array}$ & $\begin{array}{l}\text { Impact on the } \\
\text { sample }\end{array}$ \\
\hline Exclusive relationship with leisure & 6 & $66 \%$ & Important \\
\hline Relation to serious purposes & 5 & $55 \%$ & $\begin{array}{l}\text { Reasonably } \\
\text { important }\end{array}$ \\
\hline Futuristic perception, not applied to the contemporary & 4 & $44 \%$ & $\begin{array}{l}\text { Reasonably } \\
\text { important }\end{array}$ \\
\hline $\begin{array}{l}\text { Little applicability in everyday urban routine } \\
\text { (For questions of usability or system issues) }\end{array}$ & 4 & $\begin{array}{l}\text { Reasonably } \\
\text { important }\end{array}$ \\
\hline Cost-benefit of adaptation & 3 & $33 \%$ & Little important \\
\hline High investment & 3 & $33 \%$ & Little important \\
\hline $\begin{array}{l}\text { Damage to health } \\
\text { (physical and mental, eg headaches and addiction) }\end{array}$ & 2 & $22 \%$ & Little important \\
\hline $\begin{array}{l}\text { Impact on social inequality } \\
\text { (being accessible to select groups of society) }\end{array}$ & 3 & Little important \\
\hline Uselessness & $22 \%$ important \\
\hline
\end{tabular}


A strong relationship can be perceived regarding the connection of exploited technologies with entertainment, being related in 6 of the 9 studied groups.

What can be understood as pejorative, due to the use of terms that may classify the use of this technology as inferior when not used for serious purposes. Or it can be understood as a way for penetration and expansion of $\mathrm{AR}$ and VR in the population masses as it happened with other technologies.

Games such as Pokemón Go that uses augmented reality may contribute to the argumentation of the market impaction related to this technology encourage the increase of access to similar application. Also facilitate people to recognize this technology when it became usual in serious purposes.

There are many causes of bad VR. Some failures come from the limitations of technology, but many come from a lack of understanding perception, interaction, design principles, and real users. However, creating compelling VR experiences is an incredibly complex challenge (Jason, 2016).

Issues such as adaptation and applicability have emerged that can be used by the field of design as an incentive to the exploration of VR and AR. Web systems and mobile apps have been translated into punctual solutions, adding value to solving problems and popularizing these technologies worldwide. Opportunities for optimizing the usability and interaction issues surrounding the theme here are also open.

In a lower degree of impact, AR and VR technologies were underestimated from the point of view of this sampling, and related to damage in health, social hierarchy and loss of money. These topics have already been judged many times according to the literature and some are not total true. As an example, the relationship between virtual reality and health detriment, whose evidence has shown ways to circumvent this correlation (Jason, 2018). This evokes further study in order to get validated answers.

The dystopian perspective could be correlated with the lack of popularization of the real possibility of VR and AR and the lack of discussion about them. Similar to access to the Internet through personal computer and mobile that it has optimized the communication and sharing of data and information, resulting in a social improvement, with access to education and the vascularization of the economy. Once these technologies and devices were also associated with future tragedies. In fact one of the biggest points demonstrated through sample is that people cannot accept AR and VR with the contemporary reality. Delaying getting used with something that is already here.

\section{CONCLUSION}

This study served its purpose of exploration on the topic of the lack of popularity of technologies, applications and devices, involving virtual and augmented reality, from the point of view of users, potential users and never users.

Through this experiment can be seen some popular thoughts and a strong aversion to adopting immersive technologies as virtual reality. Some rely in reasons that are not supported by literature and market as damage in health, high prices, lack of usability and low appliance in everyday urban routine. This perception can be either biases or lack of perception of practical value. In fact the second option is near truth due to high levels of connection between AR and VR with leisure and entertainment purposes. Both technologies are identified mostly not as tools but as support for entertainment.

Applications that use non-immersive at all as augmented reality receive less criticism, likely to be involved in people's daily lives through other devices or media, and connection with daily challenges. This instructions can be used to conduct the industry in the spread of this technology.

The results obtained also evokes relevance of participatory design techniques. User involvement seems to be a new valuable way to consider the user in subjects that are going to affect them further. Participatory path of project support ask user not exclusively a theoretical exercise, but a new way of thinking, as basic requirement to develop solutions able to meet desires of real people (Canina, 2011).

Other point this article claims is collaborating in evidences that helps validate results from qualitative techniques as the "focus group". This method is often used in Design field and brings good insights from user perspective.

The resolutions shows the perception of local society, which has its own culture and perspective characteristics related to digital artifacts. This experiment could be replicated in order to generate similar and contrasting data. Also comparing the difference results from online and presencial sessions, and different public. 


\section{REFERENCES}

Canina, Marita; Coccioni, Elisabetta. Creating Participatory Design Tools: a Didactic Experience. INDACO Dept, Politecnico di Milano. ICORD 11: Proceedings of the 3rd International Conference on Research into Design Engineering, Bangalore, India, 2011.

Creative Research System. Sample Size Calculator. Avaliable in 2019 on https://www.surveysystem.com/sscalc.htm Jerald, Jason. Human-Centered VR Design. IEEE Computer Graphics and Applications, 2018.

Jerald, Jason. The VR Book: Human-Centered Design for Virtual Reality. Association for Computing Machinery and Morgan \& Claypool Publishers, 2016.

Martin, Bella; Hanington, Bruce. Universal Methods of Design - 100 Ways to Research Complex Problems, Develop Innovative Ideas, and Design Effective Solutions. Rockport Publishers, $1^{\circ}$ edition, United States of America, 2012.

Trends, G. E. Technologies roadshow. Gartner Identifies Top Ten Disruptive Technologies for 2008 to 2012, 2008.

Ugo Erra, Delfina Malandrino \& Luca Pepe. Virtual Reality Interfaces for Interacting with Three-Dimensional Graphs. International Journal of Human-Computer Interaction, 2018. DOI: 10.1080/10447318.2018.1429061

Vieira, Kelmara Mendes; Dalmoro, Marlon. Dilemas na Construção de Escalas Tipo Likert: o Número de Itens e a Disposição Influenciam nos Resultados? XXXII Encontro da ANPAD, Rio de Janeiro, RJ, 2008. 